\title{
Duodenal perforation in primary systemic amyloidosis
}

\author{
A G Fraser, G I Nicholson
}

Address of Hospital A G Fraser

G I Nicholson

Correspondence to: Dr A G Fraser, Academic Department of Medicine, Royal Free Hospital School of Medicine, London NW3 2QG.

Accepted for publication 11 November 199
Figure 1: Endoscopic biopsy specimen of duodenal mucosa showing heavy submucosal infiltrate of amyloid (arrows).

\begin{abstract}
Spontaneous duodenal perforation in two patients with primary systemic amyloidosis associated with multiple myeloma is described. Bowel perforation is a rare and often fatal complication of amyloidosis, and duodenal perforation has not been previously described. Both patients survived the bowel perforation with conservative management. Bowel perforation should be suspected in patients with amyloidosis presenting with acute abdominal pain, and active non-surgical management can be associated with prolonged survival.
\end{abstract}

Acute abdominal complications of amyloidosis are uncommon. Gastrointestinal involvement in amyloidosis is often asymptomatic but perhaps universal if vigorously sought. ${ }^{1}$ Reported complications include gastrointestinal haemorrhage, malabsorption, ${ }^{23}$ and pseudoobstruction. ${ }^{4}$ Other acute abdominal events include spontaneous rupture of the spleen and subcapsular haematoma of the liver.' Bowel perforation is very rare and previous reports have suggested a poor prognosis. ${ }^{35-8}$ Two patients with primary systemic (immunoglobulin ligh chain derived; AL) amyloidosis complicated by spontaneous duodenal perforation are presented.

\section{Case reports}

PATIENT I

A 65 year old man presented with anorexia, nausea, tiredness, and occasional vomiting for one week. He had been previously well, apart from hypertension treated with Atenolol and a long history of dyspepsia. A routine blood test two months previously had shown mild anaemia with a raised white blood count of $15 \times 10^{9} / 1$. A blood film showed atypical lymphoid and plasmacytoid cells. Subsequent investigation showed an immunoparesis and free kappa light chains in the serum and urine. His serum creatinine concentration was $0.13 \mathrm{mmol} / \mathrm{l}, 24$ hour urine protein excretion was $5 \cdot 1 \mathrm{~g} / \mathrm{l}$, and a bone marrow examination was requested but declined by the patient. No treatment had been given.

On examination he was clinically dehydrated. Respiratory and cardiovascular examinations were normal; the abdomen was soft with no tenderness. The haemoglobin concentration was $6.5 \mathrm{~g} / \mathrm{dl}$, white cell count $47 \cdot 1 \times 10^{9} / 1$ with $30 \%$ plasmacytoid cells, serum creatinine $1.17 \mathrm{mmol} /$ 1 , and serum calcium $2.6 \mathrm{mmol} / \mathrm{l}$. His renal function did not improve with rehydration, he remained oliguric, and peritoneal dialysis was begun. The diagnosis was plasma cell leukaemia with renal failure and he was started on melphalan $0.2 \mathrm{mg} / \mathrm{kg}$ and prednisone $2 \mathrm{mg} / \mathrm{kg}$ for four days. Three days after treatment had begun he experienced epigastric pain of sudden onset. On examination he had marked upper abdominal tenderness with guarding. A plain abdominal radiograph showed free air under the diaphragm and the suspected perforated viscus was managed conservatively. One week later, abdominal computed tomography showed a large collection in the left subphrenic space and $100 \mathrm{ml}$ of purulent material were aspirated by a percutaneous, transhepatic approach. A sinogram performed four days later showed a connection between the cavity and the duodenal cap. Upper gastrointestinal endoscopy showed some distortion of antral mucosal folds, the duodenal cap was deformed but no acute ulceration was seen. Biopsy specimens from the duodenal cap and distal duodenum showed a heavy submucosal infiltrate of amyloid (Fig 1).

The patient had a prompt response to chemotherapy, with rapid clearance of plasma cells from the peripheral blood and a gradual recovery of renal function. A barium meal four weeks after his initial presentation did not show any connection with the previous collection.

PATIENT 2

A 65 year old woman complained of loose bowel motions up to five times daily for the past nine months. Her appetite was decreased, but her 


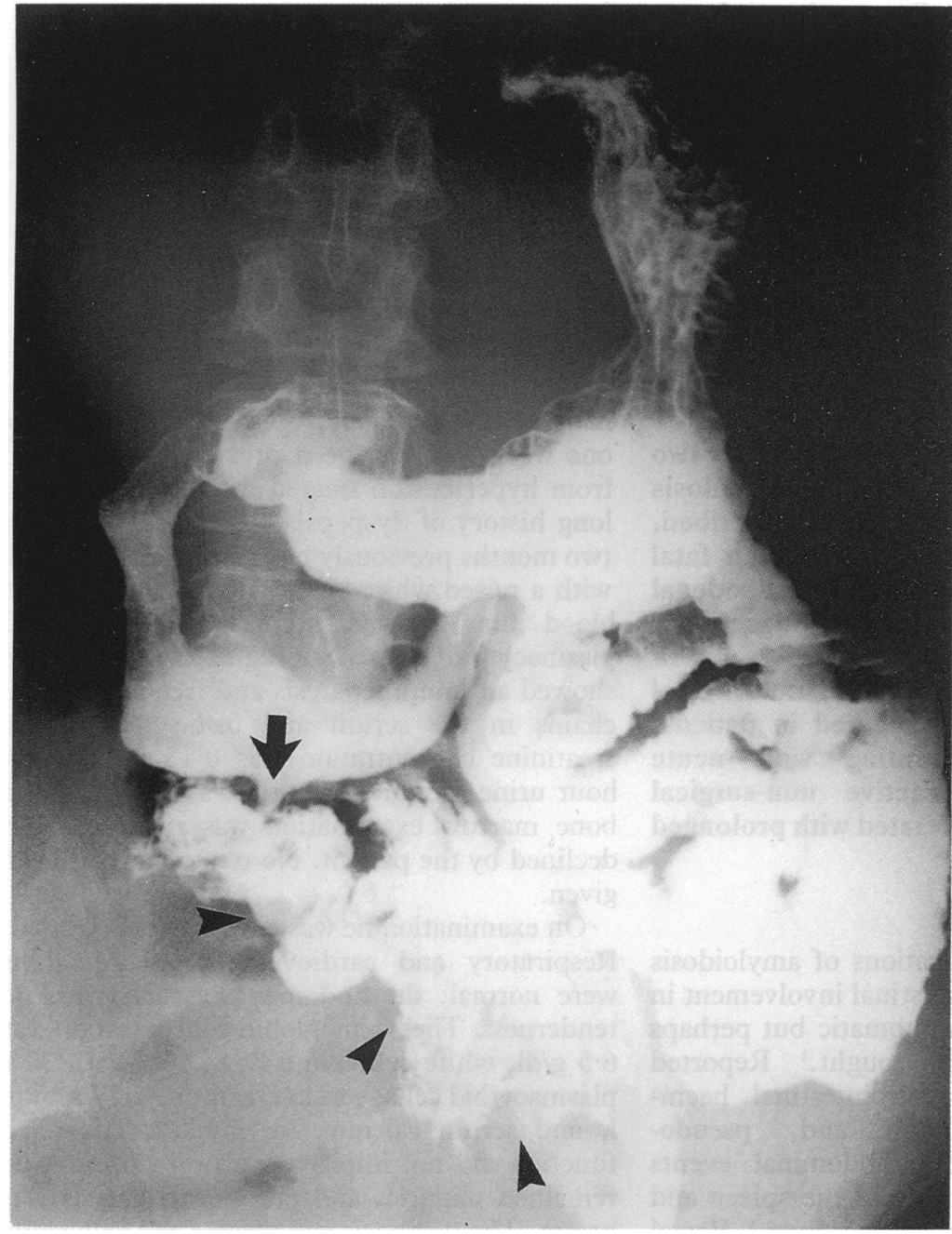

Figure 2: Small bowel enema showing sinus (large arrow) between third part of duodenum and extraluminal collection (small arrows). significant immunoparesis. She was treated conservatively, with intravenous nutrition and antibiotics, and gradually improved. A normal diet was started four weeks later, after a barium meal had shown no fistulous tract.

She has remained well for 36 months, although further investigations performed when her diarrhoea worsened showed that she had significant steatorrhoea. A therapeutic trial with tetracycline for presumed bacterial overgrowth resulted in an improvement. She now has normal bowel habit and her haemoglobin, renal function, and serum albumin are normal.

\section{Discussion}

These two patients illustrate that a successful outcome is possible after conservative treatment of spontaneous perforation of the duodenum in patients with gastrointestinal amyloidosis. Perforation of the bowel is a rare complication of amyloidosis and has usually been fatal. Five patients have been described previously; three with perforation of the small bowel and two with perforation of the rectum and colon. ${ }^{3-8}$ Only two patients survived the acute complications of the perforation and long term survival has not been previously reported.

Gastroduodenal amyloid is a relatively frequent finding in patients with gastrointestinal involvement, but is usually asymptomatic. ${ }^{9-11}$ The most common complication is haemorrhage from antral and duodenal ulceration. Occasionally pyloric obstruction occurs either from generalised thickening or a discrete mass which may resemble gastric carcinoma on a barium meal. Symptoms of epigastric discomfort suggesting peptic ulceration have been ascribed to gastroduodenal amyloidosis. However, the patients have usually had a previous history of duodenal ulcer disease. ${ }^{10}$ Spontaneous perforation of the duodenum as seen in our two patients has not been previously reported. Amyloidosis was the significant underlying pathology in both our patients, however additional factors were present. In the first patient, there was a past history of dyspepsia, and he may have had duodenal ulcer disease, although the endoscopic appearances did not show any deformity of the duodenal cap. Acute renal failure and high dose steroids are both risk factors for acute stress ulceration. The history in our second patient strongly suggested that the symptoms three weeks before admission were due to spontaneous duodenal perforation. However, it is possible that a perforation was caused by the nasojejunal tube used for the small bowel enema.

Primary systemic amyloidosis is a dysproteinaemia; up to $86 \%$ of patients will have a monoclonal protein in the serum or urine, but only $25 \%$ will have more than $10 \%$ plasma cells in the bone marrow or have the criteria for the diagnosis of multiple myeloma. ${ }^{12}$ This distinction is not always critical as the currently available treatments for myeloma do not seem to reverse the amyloid infiltration, except in some cases of renal amyloidosis. The amyloid deposit is composed of a beta pleated fibrillar protein consisting of fragments of immunoglobulin light mucosa was oedematous and friable, although the distal duodenum looked normal. Biopsy specimens of the duodenal cap and distal duodenum showed extensive amyloid in the submucosa. Subsequent investigations confirmed that she had multiple myeloma. There were free kappa light chains in the urine and a 
chains. There is a preponderance of lambda light chains; $62 \%$ lambda, $24 \%$ kappa, and $14 \%$ with no monoclonal protein in one series. ${ }^{12}$ The type of light chain does not influence the clinical presentation, with the exception that patients with kappa light chains are more likely to have nephrotic syndrome or renal insufficiency.

Non-operative management is probably preferable to laparotomy in patients with primary systemic amyloidosis as the prognosis is poor (mean survival of 20 months; five year survival $19 \cdot 6 \%){ }^{1}$ Non-operative treatment of perforated duodenal ulcers has recently been compared with operative treatment in a randomised trial, and a similar mortality was shown for both groups. ${ }^{13}$ Despite the overall poor prognosis, particularly for those patients with associated myeloma, some patients can do remarkably well as illustrated by our second patient. A more favourable outcome is seen in those patients without cardiac and renal involvement. These two patients show the need for a more positive approach to the complications of amyloidosis as an extended survival is possible. Amyloidosis is all too often regarded as an irreversible condition with grave implications. While the reports of regression of amyloidosis with treatment of the underlying disease are few, ${ }^{14}$ is the complications of amyloidosis should be actively managed.
We thank Alison MacKay for help in preparing this paper.

1 Kyle RA, Greipp PR. Amyloidosis: clinical and laboratory features in 229 cases. Mayo Clin Proc 1983; 58: 665-83.

2 O'Doherty DP, Neoptolemos JP, Wood KP. Place of surgery in the management of amyloid disease. Br F Surg 1987; 74: 83-8

3 Gilat T, Spiro HM. Amyloidosis and the gut. Am $\mathcal{F}$ Dig Dis 1968; 13: 619-33.

4 Fraser AG, Arthur JI, Hamilton I. Intestinal pseudoobstruction secondary to amyloidosis responsive to cisapride. Dig Dis Sci 1991; 36: 532-5.

5 Akbarian M, Fenton J. Perforation of small bowel in amyloidosis and review of literature. Arch Intern Med 1964; 114: 815-21.

6 Griffel B, Man B, Kraus L. Selective massive amyloidosis of the small intestine. Arch Surg 1975; 110: 215-7.

7 Ioachim N, McKenna PJ, Delaney WE, Toth I, Chung FJ. Cryoglobulinemia and amyloidosis associated with intestinal lymphoma. Arch Intern Med 1978; 138: 1158-60.

8 Sanchez JA, Molinero RM, Sayans JD, Sanchez FJ. Colonic perforation by amyloidosis. Dis Colon Rectum 1989; 32: 437-440.

9 Merrill RS. Gastrointestinal manifestations of amyloidosis $\mathrm{Am}$ f Dig Dis 1966; 11 : 489-92.

10 Cooley RN. Primary amyloidosis with involvement of the stomach. Am F Roentgenol 1953; 70: 428-38.

11 Carlson HC, Breen JF. Amyloidosis and plasma cell dyscrasias: gastrointestinal involvement. Semin Roentgenol 1986; 21: 128-38.

12 Gertz MA, Kyle RA. Primary systemic amyloidosis - a diagnostic primer. Mayo Clin Proc 1989; 64: 1505-19.

13 Crofts TJ, Park KGM, Steele RJC, Chung SSC, Li AK. A randomised trial of non-operative treatment for perforated randomised trial of non-operative treatment
peptic ulcer. NEng $\mathcal{F}$ Med 1989; 320: 970-3.

14 Kyle RA, Wagoner RD, Holley KE. Primary systemic amyloidosis: resolution of the nephrotic syndrome Melphalan and Prednisone. Arch Intern Med 1982; 142: 1445-7.

15 Schattner A, Varon D, Green L, Hurwitz N, Bentwich Z. Primary amyloidosis with unusual bone involvement: reversibility with Prednisone, Melphalan and Colchicine. Am ₹ Med 1989; 86: 3147-9. 